\title{
Role of Ovarian Markers in Predicting Pregnancy Rates in Infertile Patients Undergoing ICSI Cycle
}

\author{
Ahmed M. Nasef, Mohamed A. Mohamed, Mohamed Anwar El-Noury, Tarek I. Edris \\ Department of gynecology and \\ obstetrics, Benha faculty of \\ medicine, Benha University, \\ Egypt \\ Correspondence to: Ahmed \\ M. Nasef , Department of \\ gynecology and obstetrics, \\ Benha faculty of medicine, \\ Benha University, Egypt . \\ Abstract \\ Background: Prediction of ovarian reserve has long been the golden \\ key of reproductive endocrinology. Various endocrine [follicle \\ stimulating hormone (FSH), inhibin B, estradiol (E2) etc.], and \\ ultrasound tests [ovarian volume, antral follicle counts (AFC)] have \\ been suggested to improve prediction of oocyte yield and pregnancy \\ outcome following assisted reproductive technologies (ART). Purpose \\ Email: \\ to investigate whether serum anti-mullerian hormone (AMH), follicle \\ Received: 24 May 2021 \\ Accepted: 5 June 2021 \\ stimulating hormone (FSH), or antral follicle count (AFC) carry a \\ predictive role for clinical pregnancy in intracytoplasmic sperm \\ injection (ICSI) patients. Methods: Serum AMH, FSH and AFC of \\ 100 women under 40 years of age were investigated in this study. \\ Pregnant and non-pregnant women were compared. Results: 33 (33\%) \\ chemical pregnancies were observed in 100 women. Clinical \\ pregnancy was found in 21 women $(63.6 \%)$ of chemical pregnancy. Conclusion: we concluded \\ that Serum AMH was proved to be the most effective predictor in this study. Serum FSH was not \\ significant for both poor \& high response groups. AFC was very helpful\& cheap method for \\ prediction.
}

\section{Keywords AMH, FSH, AFC, ICSI}

List of abbreviations FSH: follicle stimulating hormone, E2: estradiol, AFC: antral follicle count, ART: assisted reproductive techniques, IVF: invitro fertilization, AMH: antimullerian hormone, BMI: body mass index, PCOs: polycystic ovary syndrome, ELISA: enzyme linked immunosorbent assay, GnRH: gonadotropin releasing hormone, SPSS: statistical package for the social sciences, LH: luteinizing hormone, SD: standard deviation, TVS: transvaginal ultrasound, ICSI: intracytoplasmic sperm injection, ROC: receiver operating characteristic, 


\section{Introduction}

The reproductive capacity of a woman depends on many factors. Prediction of ovarian reserve has long been the golden key of reproductive endocrinology. Various endocrine [follicle stimulating hormone (FSH), inhibin B, estradiol (E2) etc.], and ultrasound tests [ovarian volume, antral follicle counts (AFC)] have been suggested to improve prediction of oocyte yield and pregnancy outcome following assisted reproductive technologies (ART) [1]. Currently, most in vitro fertilization (IVF) clinicians determine starting doses of gonadotropin in the first cycle of IVF based principally on the patient's age and basal FSH levels [2]. The established predictors of reproductive potential during infertility treatment are maternal age [3, 4], early follicular phase FSH concentrations [5, 6], and less popularly, serum inhibin B concentration [7]. None of these parameters is a particularly reliable predictor of the number or quality of oocytes remaining within the ovary, or the likelihood of pregnancy from infertility treatment. Recently, interest in the use of antimüllerian hormone (AMH) and $\mathrm{AFC}$ to predict patient response to ovarian stimulation has been intense [8].
A relatively new marker, $\mathrm{AMH}$, was first identified as a specific protein in Sertoli cells of fetal testis, which inhibits the development of the mullerian duct [9]. $\mathrm{AMH}$, a member of the transforming growth factor-beta super-family, is only produced by the granulosa cells surrounding preantral and small antral follicles in the ovary [10, 11]. AMH has been shown to decrease the sensitivity of preantral and small antral follicles to FSH [12], and its production is independent from that of FSH. AMH expression decreases during the FSHdependent final stages of follicular growth [13] and atretic follicles don't express AMH [14]. Serum AMH levels decrease throughout reproductive life and are undetectable in post menopause. Body mass index (BMI) does not seem to have an effect on serum AMH levels in reproductive age women, both with and without polycystic ovary syndrome (PCOS) [15]. There have been several studies about the relationship between AMH and oocyte or embryo quality [16-18].The role of AMH in predicting pregnancy rates in normal responders has not been fully addressed in the literature. The aim of this cross-sectional study was to evaluate the association between AMH levels and pregnancy rates as well as to 
discover the highest pregnancy rates according to AMH levels.

\section{Materials and methods}

One-hundred consecutive women who were admitted to a special fertility center from March 2018 to December 2018 were enrolled in our prospective cohort study. The study was done after agreement of our (IRB). The inclusion criteria were as follows: <40 years old, FSH <12 mIU/mL, normal BMI $\left(20-25 \mathrm{~kg} / \mathrm{m}^{2}\right)$. The exclusion criteria were current or past diseases such as hepatic, renal, adrenal or thyroid disorders, affecting ovaries or gonadotropin or sex steroid secretion, clearance, or excretion, PCOs and male factor.

No woman reported use of any medication that could interfere with the normal function of the hypothalamic pituitary-gonadal axis during the last three months. In all women, body weight and height were measured; BMI was calculated with electronic digital scales (Mercury, AMZ 14, Tokyo, Japan) and in light clothing; height was measured barefoot with a stadiometer (G-Tech International CO LTD, Kyonggi Province, Korea).

Blood samples were collected during the early follicular phase of menses in all women. AMH, FSH, E2 were measured in all women.

AMH concentrations were measured with an enzymatically amplified two-sided immunoassay [DSL-10-14400 Active Müllerian Inhibiting Substance/AMH enzyme linked immunosorbent assay (ELISA) kit, Diagnostic Systems Laboratories (DSL), Webster, TX]. The theoretical sensitivity of the method is 0.006 $\mathrm{ng} / \mathrm{ml}$, the intra-assay coefficient of variation for high values is $3.3 \%$, and the interassay coefficient of variation for high values is $6.7 \%$.

Serum E2 and FSH were measured on a Roche E-170 automated immunoassay analyzer. Between-batch coefficients of variation for these assays were $10 \%$. 17hydroxyprogesterone (OH-P) was measured by RIA with intra-assay $\mathrm{CV}$ less than 7\% (DSL, Webster, TX). TSH was measured by colorimetric immunoassay (Dimension RxL clinical chemistry analyzer; Dade, Newark, DE) with a sensitivity of $0.01 \mathrm{mIU} / 1$, a precision of less than $6.2 \%$ at all concentrations tested and calibrated for the range of $0.01-50 \mathrm{mIU} / 1$. The manufacturer's reference range was 0.34-4.82 mIU/l.

Transvaginal ultrasound scans of the ovaries were performed by experienced 
sonographers who participated in the study. The presence of polycystic ovaries was diagnosed by the appearance of 12 or more follicles in each ovary measuring $2-9 \mathrm{~mm}$ in diameter and/or increased ovarian volume $\left(>10 \mathrm{~cm}^{3}\right)$. The presence of polycystic ovary syndrome (PCOS) was diagnosed by the Rotterdam-2003 criteria.

All patients in the study used the long protocol, in which the patients started the cycle of treatment by oral contraceptive pills on the first day of the preceding the cycle. Down-regulation started on day 21 of the same cycle by daily injections of GnRH agonist (Decapeptyl 0.1 mg S.C., Ferring, Germany). Down-regulation evidenced by: U/S picture; no follicle more than $10 \mathrm{~mm}$ in diameter \& hormonal profile; serum Oestradiol level less than $50 \mathrm{pg} / \mathrm{ml}$ ). Generally, the initial dose of gonadotropins was based on the individual's age, BMI and basal FSH. Doses were then administered and adjusted according to the patient's response. Monitoring was performed with serial vaginal ultrasound and plasma Oestradiol measurement (on days 7 and 9 of ovarian stimulation and every 1 or 2 days thereafter, as required). Final oocyte maturation was achieved by hCG (Choriomon 10,000 IU, IBSA) when three or more follicles measuring at least $18 \mathrm{~mm}$ in diameter. Transvaginal oocyte retrieval was performed under general anaesthesia 35 hours later. Embryo transfer had been carried on the 3rd day post ovum pick up. All patients received daily vaginal progesterone (Prontogest, $200 \mathrm{mg}$, twice daily) for luteal phase support starting from the day of oocytes retrieval until the day of pregnancy test (14 days after embryo transfer). Serum B-HCG level was assessed 14 days after embryo transfer (the chemical pregnancy) and the result was not regarded as being positive except for values exceeding $50 \mathrm{IU} /$ litre. Clinical pregnancies were confirmed by the presence of a gestational sac with fetal cardiac activity on vaginal ultrasound examination 4-6 weeks after embryo transfer.

\section{Statistical Analysis:}

The data have been presented as the arithmetical means and the standard deviations were calculated for each group as well. An independent sample t-test was performed for evaluating the statistical relations between the subgroups. A p-value $<0.05$ was considered statistically significant. All statistical analyses were performed using the Statistical Package for the Social Sciences (SPSS) software version 15.0 . 


\section{Results}

Thirty-three (33\%) chemical pregnancies were observed in 100 women and about 21 women showed clinical pregnancies. Basal FSH ranged from 1.2 IU/ml-11 IU/ml with mean of $8.1 \mathrm{IU} / \mathrm{ml}$ and $\mathrm{SD}$ of $8.5 \mathrm{IU} / \mathrm{ml}$. Basal AMH ranged from $0.4 \mathrm{ng} / \mathrm{ml}-2.5$ $\mathrm{ng} / \mathrm{ml}$. Stimulation duration ranged from 1014 days with a mean 12.4 days and SD 0.9. AFC ranged from 12-18 with a mean 14.3 and SD 1.7. Serum Progesterone on trigger day ranged from $0.03 \mathrm{ng} / \mathrm{ml}-1.2 \mathrm{ng} / \mathrm{ml}$. Number of MII oocytes ranged from (2-25), with a mean (7.5) and SD (4.9). Number of embryos transferred ranged from 1-4, with a mean and SD 2.6 and 1.5 respectively, as shown in (table1).

The mean age in all patients was 31.6 \pm 5.3 years. In the pregnant group the mean age was 29.4 year \pm 5.4 , in the non pregnant group it was 32.6 years \pm 5.0 years respectively $\quad(p=0.004$. $)$ The average duration of infertility was 3.9 years with SD 2. In pregnant patients it was $3.2 \pm 1.7$ years while in non-pregnant group it was $4.3 \pm 2.0$ years with statistically significant difference( $p=$ value 0.007$)$. The mean value of FSH among patients was $8.1 \mathrm{IU} / \mathrm{ml}$. In the pregnant group it was $7.5 \mathrm{IU} / \mathrm{ml}$ while 9.3 $\mathrm{IU} / \mathrm{ml}$ in the non-pregnant group ( $\mathrm{p}=$ value
$0.5)$. The mean value of serum estradiol the day of HCG injection was $2239.43 \mathrm{pg} / \mathrm{ml}$ in all patients. In pregnant patients it was 2580 $\mathrm{pg} / \mathrm{ml}$ and in non-pregnant it was $874.2 \mathrm{pg}$ $/ \mathrm{ml}(\mathrm{p}=$ value 0.000$)$. The mean value of serum AMH day 3 was $1.5 \mathrm{ng} / \mathrm{ml}$, in all patients it was $3.1 \mathrm{ng} / \mathrm{ml}$ in the pregnant group and $0.8 \mathrm{ng} / \mathrm{ml}$ in the non-pregnant group $(\mathrm{p}=$ value $<0.001)$. The mean AFC was 15.4 in pregnant patients and 13.8 and in non-pregnant $(\mathrm{p}=$ value $<0.001)$. The mean value of serum Progesterone day HCG injection was $0.5 \mathrm{ng} / \mathrm{ml}$ in all patients 0.35 $\mathrm{ng} / \mathrm{ml}$ in pregnant $0.51 \mathrm{ng} / \mathrm{ml}$ in nonpregnant with highly significant statistical difference ( $p=$ value 0.003 ), as shown in (table2).

The ability of AMH to predict the good responders was as follow; Area under ROC curve 0.900, Optimum cut-off point: selected $>1.29$, Area under the curve is $95 \%$ is confidence interval $(0.836-0.963)(\mathrm{P}=$ value $<0.001 \mathrm{HS}$ ), Cutoff value is $1.3 \mathrm{ng} / \mathrm{ml}$ where at that value sensitivity $81.8 \%$ and specificity $91.0 \%$, Positive predictive value PPV $81.8 \%$, Negative predictive value NPV $91.0 \%$ with Accuracy $88.0 \%$. (figure1) (Table $3 \& 4$ ). 
The ability of AFC to predict good responders was as follow; Area under ROC curve 0.767. Optimum cut-off point: selected $>14$. Area under curve is $95 \%$ (0.674-0.895) the value of testing AFC in predicting response is high $(\mathrm{P}=$ value $<0.001)$. Cut of value is $>14$ where is at the value. The sensitivity is $100.0 \%$ and specificity is $34.3 \%$. PPV: $42.9 \%$ NPV: 100.0\%. ACCURACY $=56.0 \%$. (figure2) (Table 5 \& 6).

Table 1: Hormones and Outcomes of hormonal stimulation

\begin{tabular}{|c|c|c|c|c|c|c|}
\hline & Range & & Mean & $\pm s$ & & Median \\
\hline FSH $I U / m l$ (Basal) & 1.2 & $-\quad 11$ & 8.1 & \pm & 8.5 & 6 \\
\hline LH (IU/mL) & 2.1 & -15 & 10.0 & \pm & 9.9 & 6.5 \\
\hline AMH $n g / m l$ & 0.4 & -2.5 & 1.5 & \pm & 1.8 & 0.815 \\
\hline $\mathbf{A F C}(\mathrm{mm})$ & 12 & -18 & 14.3 & \pm & 1.7 & 14 \\
\hline No. Stimulation days & 10 & -14 & 12.4 & \pm & 0.9 & 12 \\
\hline$S$ progesterone ( on trigger day ) $(\mathrm{ng} / \mathrm{mL}$ ) & 0.03 & $-\quad 1.2$ & 0.5 & \pm & 0.2 & 0.4 \\
\hline S. E2 on hCG day $(\mathrm{pg} / \mathrm{mL})$ & 1100 & -2450 & 2239 & \pm & 1714 & 22370 \\
\hline NO. MII Oocyte & 2 & -25 & 7.5 & \pm & 4.9 & 6 \\
\hline NO. Transferred Embryos & 1 & -4 & 2.6 & \pm & 1.5 & 2 \\
\hline No. cryopreserved embryos & 0 & -10 & 0.5 & \pm & 1.8 & 0 \\
\hline
\end{tabular}

Table 2: Comparison between pregnant group \& non-pregnant group:

\begin{tabular}{lllllll}
\hline & \multicolumn{7}{c}{ Pregnant group } & \multicolumn{3}{c}{ Non pregnant group } & P value \\
& Mean & SD & Mean & SD & \\
\hline & & & & & & \\
Age (years) & 29.4 & \pm & 5.4 & 32.6 & \pm 5.0 & $0.004 \mathrm{HS}$ \\
Infertility Duration (years) & 3.2 & \pm & 1.7 & 4.3 & \pm 2.0 & $0.007 \mathrm{HS}$ \\
FSH $\mathbf{I} \boldsymbol{U} / \boldsymbol{m l}$ (Basal) & 7.5 & \pm & 5.9 & 9.3 & \pm 12.3 & $0.5 \mathrm{NS}$ \\
AMH $\boldsymbol{n g} / \boldsymbol{m l}$ & 3.1 & \pm & 2.2 & 0.8 & \pm 0.9 & $<0.001 \mathrm{HS}$ \\
AFC ( $\mathbf{m m}$ ) & 15.4 & \pm & 1.3 & 13.8 & \pm 1.6 & $<0.001 \mathrm{HS}$ \\
Stimulation Duration(days) & 12.6 & \pm & 0.9 & 12.2 & \pm 0.9 & $0.04 \mathrm{~S}$ \\
Progesterone ( trigger day ) & 0.35 & \pm & 0.19 & 0.51 & \pm 0.25 & $0.003 \mathrm{HS}$ \\
E2 $\mathbf{p g} / \boldsymbol{m l}$ ( trigger day ) & 2580 & \pm & 11.1 & 874.2 & \pm 13.2 & $0.0 \mathrm{NS}$ \\
\hline
\end{tabular}


Table 3: AMH area under the curve and $\mathrm{p}$ value

\begin{tabular}{|c|c|c|c|}
\hline Test variable & AUC & $95 \% \mathrm{CI}$ for $\mathrm{AUC}$ & $\mathrm{P}$ value \\
\hline AMH & 0.900 & $0.836-0.963$ & $<0.001 \mathrm{HS}$ \\
\hline
\end{tabular}

Table 4: $\mathrm{PPV}=$ positive predictive value, $\mathrm{NPV}=$ negative predictive value.

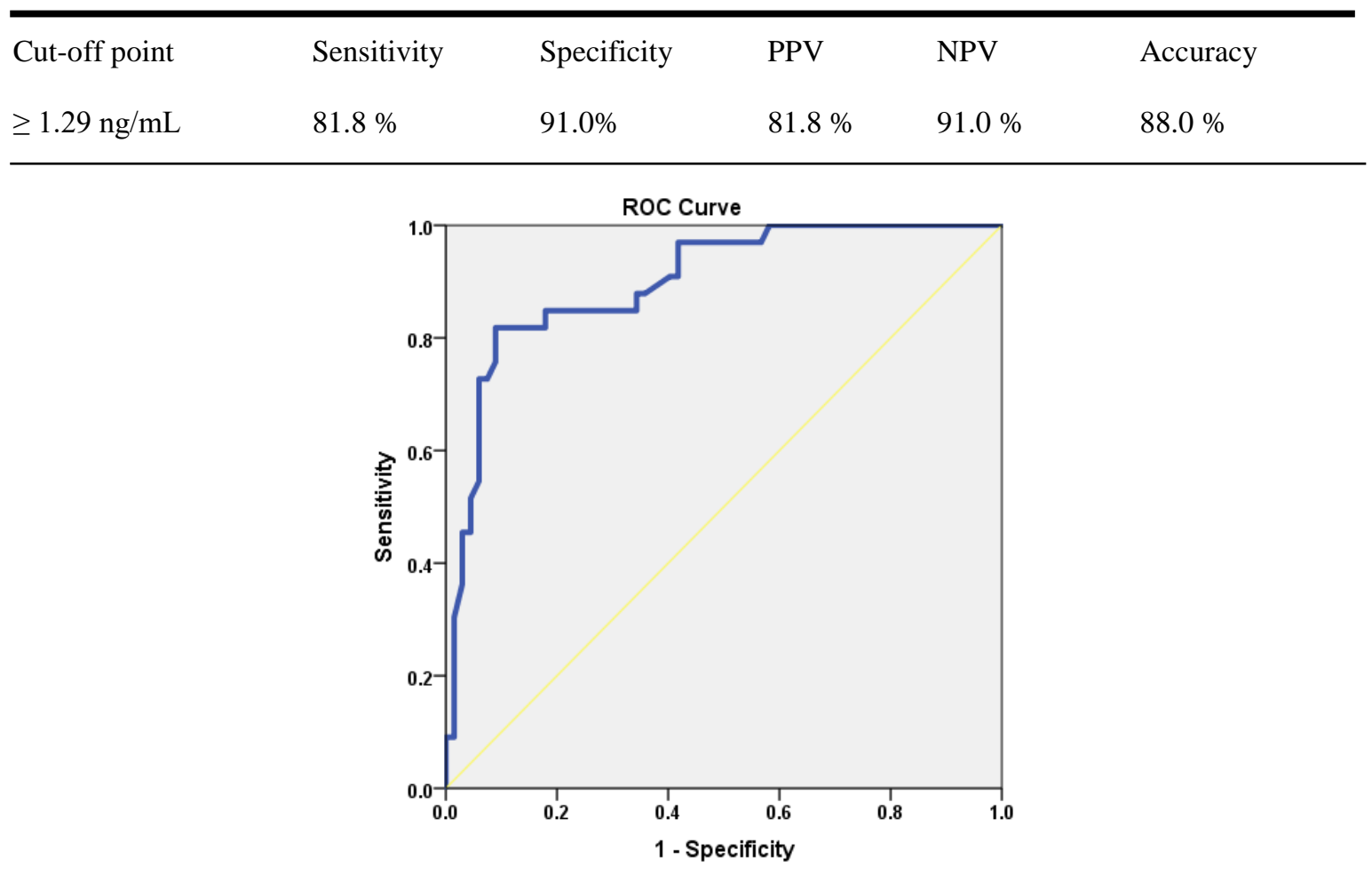

Figure 1

Table 5: $A U C=A r e a$ under the curve, $C I=$ confidence interval.

\begin{tabular}{llll}
\hline Test variable & AUC & $95 \%$ CI for AUC & P value \\
AF count & 0.767 & $0.674-0.859$ & $<0.001$ \\
& & & HS \\
\hline
\end{tabular}

Table 6: $P P V=$ positive predictive value,

\begin{tabular}{llllll}
\hline NPV= negative predictive value. & & & \\
Cut-off point & Sensitivity & Specificity & PPV & NPV & Accuracy \\
$\geq 14$ & $100.0 \%$ & $34.3 \%$ & $42.9 \%$ & $100.0 \%$ & $56.0 \%$ \\
\hline
\end{tabular}




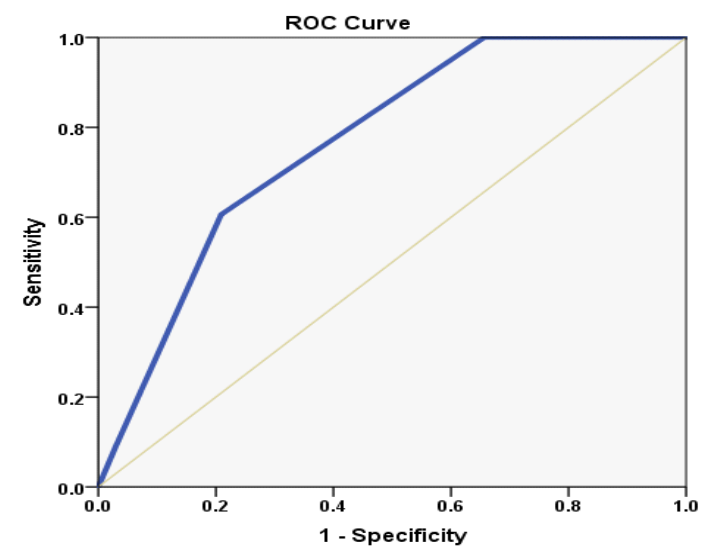

Figure 2

\section{Discussion}

The antral follicle count (AFC) was studied as an ovarian reserve in our study. It is defined as the total number of follicles, which can be stimulated under maximal ovarian stimulation with FSH. Ovarian reserve tests are supposed to indirectly reflect the size of the small antral follicles (2-10 $\mathrm{mm}$ in diameters) in the ovary. Thus, a decrease in follicle number increases the risk of poor response after ovarian hyperactive stimulation in IVF patients at an older age (19\& 20).

In our study, to determine the diameter of the follicle, the mean of measurements in two perpendicular directions were taken. The follicles were visualized and counted by TVS in the early follicular phase are 2-10 $\mathrm{mm}$ in size according to (20). In our results, the mean AFC was 13.8 in the non-pregnant group and 15.4 in the pregnant $(\mathrm{p}<0.001)$. In
ROC curve analysis, the area under the curve was $>75 \%(0.767)$. The value of testing AFC in predicting response is high with an optimum cut-off point >14, sensitivity and specificity were $100 \%$ and $34.3 \%$ respectively and accuracy was $56.0 \%$.

In a study done in 2010 that included 162 infertile patients, the mean AFC was 8.9+ $5.2 \mathrm{~mm}$; the $25^{\text {th }}$ and $75^{\text {th }}$ percentile were 5 and 10.5, respectively (21). In a study done in 2009 concluded that day $3 \mathrm{AMH}$ and AFC were significantly higher in pregnant group compared to non-pregnant group (total 60 infertile women). This study had a small number of patients. AFC mean value in patients with positive fetal pulsation at 7 or 8 weeks was 15.8 while in cases with negative pulsations $14.7(\mathrm{p}=0.01)(22)$. 
AFC was found to be superior to the ovarian volume measurement. A recent metaanalysis was conducted including a total of 10 studies on ovarian volume and 17 studies on AFC. The AFC performed significantly better than ovarian volume in the prediction of poor response. The overall accuracy for predicting non-pregnancy was poor for both tests. The clinical value in poor response prediction was only evident for the AFC as a considerable number of cases could be identified who will have a high chance of producing a poor response to stimulation. The clinical value for non-pregnancy was virtually absent for both tests (23).

According to a study done in 2014 upon 123 cases undergoing ICSI, a cut-off value of $\mathrm{AMH}$ ranging between $0.7-1.3 \mathrm{ng} / \mathrm{ml}$ may be considered acceptable for the prediction of poor response in IVF. The mean value of basal FSH among patients was $8.1 \mathrm{IU} / \mathrm{ml}$. In good responders it was $7.5 \pm 2.9 \mathrm{IU} / \mathrm{ml}$ and $9.3 \pm 3.3 \mathrm{IU} / \mathrm{ml}$ in poor responders $(\mathrm{p}=0.5)$ (24). Lack of a clear cut-off point, huge variations between different laboratories and monthly variations in FSH secretion means that, FSH measurement is of only limited value in assessing the prognosis of IVF treatment (25).

Another study suggested that combination of basal FSH and age to be better than age alone in predicting IVF outcomes but this was limited by lack of clear cut-off point, monthly variation and disparities between different laboratory assays (26).

Another study done in 2004 showed that basal FSH measurement and clomiphene citrate challenge test had a very low sensitivity, but specificity was very high for clinical pregnancy after ART. Thus, a normal result is not useful because of its poor sensitivity and an abnormal result for FSH would be of higher predictive ability for a poor outcome for ART (27).

Another Prospective cross-sectional study in 2016 upon One hundred infertile women aimed to determine the value of mean ovarian volume, AFC, maternal age, basal $\mathrm{FSH}$ and $\mathrm{AMH}$ in infertile patients undergoing ovulation induction or IVF cycles. Primary outcome was to predict the best parameter of ovarian reserve. AFC and $\mathrm{AMH}$ are found to correlate significantly with the ovarian response with $\mathrm{p}$ values < 0.001 and 0.03 respectively, indicating that they are good predictors of ovarian reserve. The basal FSH and ovarian volume do not correlate with the ovarian response indicating their poor value as predictors of ovarian reserve (28).

The mean value of serum AMH day 3 was $1.5 \mathrm{ng} / \mathrm{ml} \pm 1.8 \mathrm{in}$ all patients, $3.1 \mathrm{ng} / \mathrm{ml} \pm$ 
2.2 in pregnant group and $0.8 \mathrm{ng} / \mathrm{ml} \pm 0.9$ in non-pregnant group $(\mathrm{p}<0.001)$. In ROC curve analysis, area under the curve was > $75 \%$ (0.900). 95\% confidence interval for area under the curve was 0.84-0.96 ( $\mathrm{P}$ value $<0.001)$. The value of testing $\mathrm{AMH}$ in predicting response is low. At cutoff value of $>1.29 \mathrm{ng} / \mathrm{ml}$, the sensitivity was $81.8 \%$, specificity was $91.0 \%$ and accuracy was $88.0 \%$. Serum AMH day 3 was useful in predicting ovarian response. However it was not significant in predicting pregnancy. In a study upon age less than 42 years by in 2004, day 3 serum AMH level and IVF outcome were strongly associated. Higher AMH concentrations were associated with a higher clinical pregnancy rate. Moreover, they showed that AMH might offer greater prognostic value than other currently available serum markers of ART outcome (29).

A meta-analysis of 13 trials on AMH and 17 trials on AFC in 2009, showed that sensitivities and specificities of AMH for prediction of poor ovarian response varied between $40 \%$ and $91 \%$ and between $64 \%$ and $100 \%$, respectively. Moreover, the receiver operating characteristic(ROC) curves did not suggest a clearly better predictive ability for AMH than AFC, and the difference was not statistically significant $(\mathrm{P}=0.73)$. The authors concluded that AMH had at least the same level of accuracy and clinical value for the prediction of poor response and nonpregnancy as AFC. This agreed with our study (30).

Only few studies suggested that serum AMH was not associated with ongoing pregnancy rates. A study done in 2003 suggested that day $3 \mathrm{AMH}$ levels could predict the number of oocytes retrieved, but not the likelihood of pregnancy (31).

Prediction of poor ovarian reserve is not the same thing as predicting ongoing pregnancy. In a previous study, the authors found that an AMH cut-off level of $2 \mathrm{ng} / \mathrm{ml}$ could predict poor response with sensitivity of $78.9 \%$ and specificity of $73.8 \%$ (32). In another study, the authors found that an AMH cut-off level of $3.3 \mathrm{ng} / \mathrm{ml}$ predicted ovarian hyperactive stimulation syndrome (OHSS) with a sensitivity of $90 \%$ and a specificity of $71 \%$ (33). In our study, AMH cut-off level $>1.29 \mathrm{ng} / \mathrm{ml}$ could predict poor response with sensitivity of $81.8 \%$ and specificity of $91.0 \%$. Serum AMH level seems to be a quantitive marker of the ovary but not a quality factor. Serum AMH level does not seem to be a prognostic factor for ongoing pregnancy rates in IVF cycles (33). 
Means of AMH differ in various studies. The most striking study on means of $\mathrm{AMH}$ in general population was the study of Tremellen and kolo in 2010. They evaluated a total of 1032 women aged between 18 and 43 years and found that the mean serum $\mathrm{AMH}$ level was relatively stable at approximately $4.1 \mathrm{ng} / \mathrm{ml}$ in the under 30 years old range. However, from 30 years of age onwards, the serum AMH levels declined rapidly, halving in concentration to an average of only $1.95 \mathrm{ng} / \mathrm{ml}$ in the $35-39$ years age group (34).

A prospective study upon 60 infertile women to investigate whether AMH levels at basal \& ovulation triggering days are associated with ovarian response \& pregnancy outcome for IVF. They concluded that basal AMH was a good predictor of clinical pregnancy (35) as agreed with our study.

A study done in 2010 retrospectively investigated the relationship between IVF clinical pregnancy rates per initiated cycle and serum AMH tertile stratified by age in 1558 women in all age groups and detected that age influenced the AMH \&clinical pregnancy rate relationship. They found that for women aged >42 years with $\mathrm{AMH}<$ $0.29 \mathrm{ng} / \mathrm{ml}$, the clinical pregnancy rate was significantly lower than those of the middle and higher quartiles (36). However, our results may only be appropriate for women younger than 40 years, since older women were excluded.

\section{References}

1. Majumder K, Gelbaya TA, Laing I, Nardo LG. The use of antiMüllerian hormone and antral follicle count to predict the potential of oocytes and embryos. Eur J Obstet Gynecol Reprod Biol. 2010;150(2):166-70.

2. Borini A, Dal Prato L. (2005) Tailoring FSH and LH administration to individual patients. Reprod Biomed Online.;11:283-93.

3. Check JH, Peymer M, Lurie D. (1998) Effect of age on pregnancy outcome without assisted reproductive technology in women with elevated early follicular phase serum follicle-stimulating hormone levels. Gynecologic and Obstetric Investigation, 45, 217-220.

4. Faddy MJ, Gosden RG. (1995) A mathematical model of follicle dynamics in the human ovary. Human Reproduction, 10, 770-775.

5. Scott RT, Toner JP, Muasher SJ Oehninger S, Robinson S, Rosenwaks Z. (1989) Folliclestimulating hormone levels on cycle day 3 are predictive of in vitro fertilization outcome. Fertility and Sterility, 51, $651-654$.

6. Toner JP, Philput CB, Jones GS, Muasher SJ. (1991) Basal follicle-stimulating hormone level is a better predictor of in vitro fertilization performance than age. Fertility and Sterility, 55, 784-791. 
7. Seifer DB, Lambert-Messerlian G, Hogan J, Gardiner AC, Blazar AS, Berk CA. (1997) Day 3 serum inhibin-B is predictive of assisted reproductive technologies outcome. Fertility and Sterility, 67, 110-114

8. Lekamge DN, Barry M, Kolo M, Lane M, Gilchrist RB, Tremellen KP. (2007) AntiMüllerian hormone as a predictor of IVF outcome. Reprod Biomed Online.;14(5):602-10

9. Josso N. (2008) Professor Alfred Jost: the builder of modern sex differentiation. Sex Dev.;2(2):5563. Epub 2008 Jun 20.

10. Durlinger AL, Visser JA, Themmen AP. (2002) Regulation of ovarian function: The role of antimüllerian hormone. Reproduction.;124: 601-9

11. La Marca A, Broekmans FJ, Volpe A, Fauser BC, Macklon N. (2009), ESHRE Special Interest Group for Reproductive Endocrinology-AMH Round Table: Anti-Mullerian hormone (AMH): what do we still need to know? Hum Reprod, 24:2264-2275.

12. Durlinger ALL, Gruijters MJG, Kramer P, Karels B, Kumar TR, Matzuk MM, et al. (2001) Anti-mullerian hormone attenuates the effect of FSH on follicle development in the mouse ovary. Endocrinology;142:4891-9.

13. Weenen C, Laven JSE, von Bergh ARM, Cranfield M, Groome NP, Visser JA, et al. (2004) Antimullerian hormone expression pattern in the human ovary: potential implications for initial and cyclic follicle recruitment. Mol Hum Reprod;10:77-83.
14. Baarends WM, Uilenbroek JT, Kramer P, Hoogerbrugge JW, van Leeuwen EC, Themmen AP, et al. (1995) Antimullerian hormone and antimullerian hormone type 2 receptor messenger ribonucleic acid expressions in rat ovaries during postnatal development, the estrous cycle and gonadotropin-induced follicle growth. Endocrinology;136:4951-62.

15. Sahmay S, Guralp O, Senturk LM, Imamoglu M, Kucuk M, Irez T. Serum anti-mullerian hormone concentrations in reproductive age women with and without polycystic ovary syndrome: the influence of body mass index. Japan Society for Reproductive Medicine. 2011.

16. Ebner T, Sommergruber M, Moser M, Shebl O, Schreier-Lechner E, Tews G. (2006) Basal level of anti-mullerian hormone is associated with oocyte quality in stimulated cycles. Hum Reprod;21: 2022-6.

17. FongSL, Baart EB, Martini E Schipper I, Visser JA, Themmen AP, de Jong FH, et al. (2008) Antimullerian hormone: a marker for oocyte quantity, oocyte quality and embryo quality. Reprod Biomed Online;16: 664-70.

18. Irez T, Ocal P, Guralp O, Cetin M, Aydogan B, Sahmay S. Different serum anti-Müllerian hormone concentrations are associated with oocyte quality, embryo development parameters and IVF-ICSI outcomes. Arch Gynecol Obstet. 2011;284(5):1295-301.

19. Meskhi, A., \& Seif, M. W. (2006). Premature ovarian failure. Current Opinion in Obstetrics and Gynecology, 18(4), 418-426. 
20. Kwee, J., Elting, M. E., Schats, R., McDonnell, J., \& Lambalk, C. B. (2007). Ovarian volume and antral follicle count for the prediction of low and hyper responders with in vitro fertilization. Reproductive Biology and Endocrinology, 5(1), 9.

21. Majumder, K., Gelbaya, T. A., Laing, I., \& Nardo, L. G. (2010). The use of anti-Müllerian hormone and antral follicle count to predict the potential of oocytes and embryos. European Journal of Obstetrics \& Gynecology and Reproductive Biology, 150(2), 166-170.

22. Wu, C. H., Chen, Y. C., Wu, H. H., Yang, J. G., Chang, Y. J., \& Tsai, H. D. (2009). Serum antiMüllerian hormone predicts ovarian response and cycle outcome in IVF patients. Journal of assisted reproduction and genetics, 26(7), 383-389.

23. Hendriks, D. J., Kwee, J., Mol, B. W., te Velde, E. R., \& Broekmans, F. J. (2007). Ultrasonography as a tool for the prediction of outcome in IVF patients: a comparative metaanalysis of ovarian volume and antral follicle count. Fertility and sterility, 87(4), 764-775.

24. Aboulghar M (2014). Antimullerian hormone in the management of infertility. Middle East Fertility Society Journal. 19. 10.1016/j.mefs. 2014.03.002.

25. La Marca, A., Sighinolfi, G., Radi, D., Argento, C., Baraldi, E., Artenisio, A. C., et,al. (2009). Anti-Müllerian hormone (AMH) as a predictive marker in assisted reproductive technology (ART). Human reproduction update, 16(2), 113130.
26. Johnson, N. P., Bagrie, E. M., Coomarasamy, A., Bhattacharya, S., Shelling, A. N., Jessop, S, et,al. (2006). Ovarian reserve tests for predicting fertility outcomes for assisted reproductive technology: the International Systematic Collaboration of Ovarian Reserve Evaluation protocol for a systematic review of ovarian reserve test accuracy. BJOG: An International Journal of Obstetrics \& Gynaecology, 113(12), 1472-1480.

27. Jain, Tarun, Michael R. Soules, and John A. Collins. "Comparison of basal follicle-stimulating hormone versus the clomiphene citrate challenge test for ovarian reserve screening." Fertility and sterility 82.1 (2004): 180-185.

28. Islam, Y., Aboulghar, M. M., AlEbrashy, A. E. D., \& Abdel-Aziz, O. (2016). The value of different ovarian reserve tests in the prediction of ovarian response in patients with unexplained infertility. Middle East Fertility Society Journal, 21(2), 69-74.

29. Hazout, A., Bouchard, P., Seifer, D. B., Aussage, P., Junca, A. M., \& Cohen-Bacrie, P. (2004). Serum antimüllerian hormone/müllerianinhibiting substance appears to be a more discriminatory marker of assisted reproductive technology outcome than follicle-stimulating hormone, inhibin B, or estradiol. Fertility and sterility, 82(5), 1323-1329.

30. Broer, S. L., Mol, B. W. J., Hendriks, D., \& Broekmans, F. J. (2009). The role of antimullerian hormone in prediction of outcome after IVF: comparison with the antral follicle count. Fertility and sterility, 91(3), 705-714. 
31. Deffieux, X., and J. M. Antoine. "Inhibins, activins and anti-Müllerian hormone: structure, signalling pathways, roles and predictive value in reproductive medicine." Gynecologie, obstetrique \& fertilite 31.11 (2003): 900-911

32. Sahmay, S., Cetin, M., Ocal, P., Kaleli, S., Senol, H., Birol, F., et,al. (2011). Serum anti-Müllerian hormone level as a predictor of poor ovarian response in in vitro fertilization patients. Reproductive medicine and biology, 10(1), 9-14.

33. Ocal, P., Sahmay, S., Cetin, M., Irez, T., Guralp, O., \& Cepni, I. (2011). Serum anti-Müllerian hormone and antral follicle count as predictive markers of OHSS in ART cycles. Journal of assisted reproduction and genetics, 28(12), 11971203.

34. Tremellen, Kelton, and Michelle Kolo. "Serum anti-Mullerian hormone is a useful measure of quantitative ovarian reserve but does not predict the chances of live-birth pregnancy." Australian and New Zealand Journal of Obstetrics and Gynaecology 50.6 (2010): 568-572.

35. Wu, C. H., Chen, Y. C., Wu, H. H., Yang, J. G., Chang, Y. J., \& Tsai, H. D. (2009). Serum antiMüllerian hormone predicts ovarian response and cycle outcome in IVF patients. Journal of assisted reproduction and genetics, 26(7), 383-389.

36. Wang, J. G., Douglas, N. C., Nakhuda, G. S., Choi, J. M., Park, S. J., Thornton, M. H., et,al (2010). The association between anti-Müllerian hormone and IVF pregnancy outcomes is influenced by age. Reproductive biomedicine online, 21(6), 757-761.

To cite this article: Ahmed M. Nasef, Mohamed A. Mohamed, Mohamed Anwar El-Noury, Tarek I. Edris. Role of Ovarian Markers in Predicting Pregnancy Rates in Infertile Patients Undergoing ICSI Cycle. BMFJ 2021:38(3):811-824. DOI: 10.21608/bmfj.2021.77413.1421 